\title{
Inequality in Burkina Faso - To what extent do household, community and regional factors matter?
}

Forthcoming in Journal of the Royal Statistical Society: Series A (Statistics in

\author{
Society), 174 (2): 1-26)
}

Johannes Gräb (graeb@uni-goettingen.de)

Centre for Statistics, University of Göttingen, Germany and Deutsche

Bundesbank

Michael Grimm ${ }^{1}$ (grimm@iss.nl)

International Institute of Social Studies, Erasmus University Rotterdam, The Netherlands

\begin{abstract}
Empirical evidence suggests that regional disparities in income are often very wide, that these disparities do not necessarily disappear as economies grow and that these disparities are themselves a major driver of growth. We use a novel approach based on multilevel modeling to decompose the sources of inequality in household incomes in Burkina Faso. We show that income differences across space are not only explained by the spatial concentration of households with favourable characteristics but to a large extent also by disparities in community endowments. Climatic differences across regions do matter, too, but to a much smaller extent. Based on the findings, it would be worth assessing the potential effects of policies which build and enhance infrastructure that connects communities complemented by interventions targeted to specific villages that particularly lag behind.
\end{abstract}

Key words: Decomposition, Multilevel modelling, Poverty, Spatial Income Inequality, Sub-Saharan Africa.

JEL codes: C21, I32, O12, R12.

1 Corresponding author: Erasmus University Rotterdam, International Institute of Social Studies, Kortenaerkade 12, 2518AX The Hague, The Netherlands, Phone: +31-70-4260694, Fax: +31-70-4260507. 
Acknowledgements - We thank the editor, Antony Fielding, one anonymous associate editor and two anonymous referees for very helpful and constructive comments. Moreover, we thank the Institut National de la Statistique et de la Démographie (INSD) in Burkina Faso for providing the household survey data. We are also grateful to Hartmut Janus and Bakary Kindé for their great hospitality and assistance during the data collection process in Burkina Faso. The paper benefited from discussions with Channing Arndt, Luc Christiansen, Stephan Klasen, Jann Lay, Andrew McKay, Patrick Nolen, Robert Sparrow, Stefan Sperlich and Finn Tarp. Valuable comments were received at seminar presentations at Erasmus University and the University of Göttingen and at the Nordic Conference on Development Economics (Stockholm, 2008), the ESRC Conference on 'Economic Growth in Developing Countries' (Brighton, 2008), the WIDER conference on 'Frontiers of Poverty Analysis' (Helsinki, 2008), the 56th Annual North American Meetings of the Regional Science Association International (New York, 2009) as well as the Conference of the Spatial Econometrics Association (New York, 2008). All remaining errors are of course ours. Funding for this research from the German Research Foundation (DFG) is gratefully acknowledged [grant number: GR3097/1-1]. 


\section{Introduction}

Empirical evidence for low and middle-income countries suggests that regional disparities in growth and poverty are often very wide, that these regional disparities do not necessarily disappear as economies grow and develop and that these disparities are themselves a major driver of the overall performance of an economy (see, e.g., Besley and Cord (2007) and Grimm et al. (2007)). Often such regional disparities seem to be closely linked to key policy choices and, in particular, public spending and investment. But regions that lag behind also very often show adverse agroclimatic conditions and only a limited scope for non-agricultural activities (see again Besley and Cord (2007) and Grimm et al. (2007)).

Burkina Faso is one of many Sub-Saharan African countries where the regional pattern of living standards is particularly puzzling. Some of the observed inequality is correlated with cotton production, the main export commodity in Burkina Faso. However, despite the cotton boom that Burkina Faso experienced in the mid and late 1990s, some cotton producing provinces grew more slowly than other non-cotton producing provinces. In particular, the traditionally poor and arid North of the country experienced an increase in development during that period and this does not seem to have been driven by domestic or foreign aid (Grimm and Günther 2007). Hence, from these observations it is difficult to tell to what extent agro-climatic factors, trade exposure and population structure matter in terms of disparities in the level and changes in living standards within an economy like Burkina Faso. However, explaining where such disparities come from and how they change over time would seem to be important in the design of development strategies and interventions appropriate to reducing such disparities in a cost-effective way.

Standard poverty assessments usually address this question by undertaking a more descriptive analysis of growth patterns across regions or by performing decompositions of inequality indices by regional units. For instance, the Theil inequality index can be perfectly decomposed (i.e. without residual) in between and within-group components (see, e.g., McKay (2007)). However, such decompositions make it very difficult to disentangle what is due to heterogeneity in household characteristics, such as occupation and education, and what is due to heterogeneity in area-specific characteristics and endowments, such as rainfall and infrastructure. In other words, poor areas could simply be poor because households with less favourable characteristics are geographically concentrated.

To deal with this problem, Ravallion and Wodon (1999) relied on two consecutive cross-sections of household survey data for Bangladesh to run separate regressions for each year and for each of the urban and rural sectors using household expenditure per capita as the dependant variable. They included a wide range of household characteristics and attributed the remaining part of the observed variance to geographic effects. Then they undertook a number of robustness checks to exclude the possibility of a bias due to omitted household characteristics that are spatially correlated. They concluded that there were sizeable spatial differences in the rewards ('returns' hereafter) to household characteristics, i.e. the same household might have been poor in one region 
but not in the other.

Another approach was chosen by Jalan and Ravallion (2002) and later by De Vreyer et al. (2009). They used several waves of panel data in order to implement a quasi-differencing method to identify the impact of locally determined geographic and socioeconomic variables on household consumption growth while removing unobserved household and community fixed effects. These authors found, for rural China and Peru respectively, robust evidence of geographic poverty traps (locations of persisting poverty) and highlighted, in particular, the socio-economic features of villages and the provision of public goods, such as rural roads, as important area-specific determinants.

Benson et al. (2005) used spatial regression and geographically weighted regression techniques to allow regression error terms to be spatially correlated and to assess the degree to which determinants and prevalence of poverty vary across space. For rural Malawi, the authors did not find much evidence for local poverty traps, characterized, for instance, by low agricultural productivity, and emphasized that the determinants of poverty vary spatially in their effects across the country. However, they also found some evidence that regions with more opportunities for non-agricultural earnings and more markets, public infrastructure and services showed less poverty.

While all these studies suggest that poverty reduction efforts have to be targeted at the sub-national level, they do not provide a decomposition of the variance of observed living standards into components due to factors that vary within and factors that vary between spatial units. However, such an analysis is potentially of great importance as it can help to target poverty reduction policies more effectively. If the variance in living standards were due primarily to variation between spatial units, policies should target precisely these spatial units. If, in contrast, the overall variation in households' well-being was driven more by variation within certain spatial units, efforts to equalize living standards should focus more on smaller units. In practice, of course, there might be institutional reasons that make it impossible to apply this strategy. For instance, in a country with a low degree of decentralization, it may be difficult to implement programmes that are appropriately targeted at very small spatial units. Ignoring for the moment this possible limit, we propose to use multilevel random coefficient models to decompose the variance in living standards across four spatial levels: households, communities, provinces and (agro-climatic) regions. Moreover, our technique allows us to decompose the variance measured at each level into a component accounting for the variance in level-specific characteristics and components accounting for the sorting of lower-level characteristics across these levels. For instance, the variance in households' living standards between communities might be driven by the variance in community-specific endowments and by the sorting of households with favourable and unfavourable characteristics across communities. Hence, we distinguish three types of factors: household-level factors, spatial factors (on different spatial levels) and factors related to the clustering of households on various spatial levels. There are, however, a few limitations to the technique we use. First, we are not able to control for latent characteristics on any of the four levels. Unexplained variation between spatial units could, therefore, be driven either by characteristics 
on a specific spatial level itself or by unobserved lower-level factors. This has to be kept in mind when interpreting the results since neglecting it would result in an overestimation of the effects of higher-level factors. Second, clustering on characteristics of the lower-level may itself be driven by higher-level factors. This would, in turn, underestimate the importance of higher level-specific characteristics.

Multilevel modelling to address questions related to spatial inequality can be found in a few other studies. Ecob (1996) used this approach to analyze the effect of area of residence on health outcomes. Controlling for individual factors, he found an association between area of residence and individual health outcomes, suggesting that spatial characteristics matter in explaining differences in health between different spatial units. In a similar context, Merlo et al. (2005) showed, for instance, (i) how to investigate whether there is clustering in systolic blood pressure within neighbourhoods, (ii) to what extent neighbourhood differences in levels can be explained by the individual composition of the neighbourhoods, and (iii) whether the contextual phenomenon differs in magnitude for different groups of people.

In this paper we apply multilevel modelling to study inequality in living standards across spatial units. In contrast to the above mentioned studies, we include, among other things, more than two levels. We implement our approach for the case of Burkina Faso and build a very detailed and exhaustive data set combining household survey data, population census data, agricultural survey data and a number of statistics collected at the provincial level. It should be emphasized that our approach is static in nature. Moreover, our data is not georeferenced, which prevents us from accounting properly for spatial externalities and interactions, i.e. effects that affect a given geographical unit but arose in another (e.g. knowledge about agricultural production technologies) or the fact that geographically closer units may interact more than not so close units (e.g. via trade). The potential importance of such effects was highlighted, in particular, by Durlauf (1994) and Anselin et al. (2004).

The remainder of our paper is organized as follows. In Section 2 we provide the necessary background and describe spatial inequality and its development over time in Burkina Faso. In Section 3 we present our data and discuss our empirical strategy. In Section 4 we present our results. In Section 5 we conclude.

\section{Regional Growth and Inequality in Burkina Faso}

Burkina Faso is one of the poorest countries in the world. Gross domestic product (GDP) per capita based on purchasing power parity (PPP) (i.e. GDP in international prices) is estimated at only PPP Intl. \$1,213, and the country was ranked 177th out of 182 countries on the Human Development Index of the United Nations Development Programme (UNDP 2009). It is a landlocked country in the middle of West-Africa with a population of roughly 13.4 million. The population has a very low level of formal education (schooling) and the country possesses only very few natural resources. The country is highly dependent on cotton exports, which account for almost 60 percent of total export 
earnings, as well as on international aid. More than 80 percent of the Burkinabè population lives in rural areas working predominantly in the agricultural sector, which suffers from very limited rainfall and recurrent severe droughts. The country has experienced sustained growth with moderate poverty reductionmeasured as the reduction in the share of the population below the poverty line, i.e. a monetary threshold necessary to meet basic needs - during the past 15 years, albeit accompanied by major variations over time and space. All these aspects are described in more detail in Grimm and Günther (2007).

If income levels and growth rates as well as poverty measurements are compared across Burkina Faso's 13 regions (see Table 1) it can be seen that in 1994 the Western regions, where most of the country's cotton is produced-Hauts Bassins, Mouhoun and Cascades - were richer than the remaining regions (not counting the two urban centres Ouagadougou and Bobo-Diolassou). However, in terms of growth, the non-cotton and initially very poor Eastern regionsSahel, Est and Centre-Nord - have recently performed better than all cotton regions, despite the very favourable development of cotton exports and the widespread belief that cotton exports were the driver of Burkina Faso's growth (see, for example, IMF (2003)). In terms of the poverty headcount, HautsBassins has always had moderate poverty, which is due primarily to the fact that, by Burkinabè standards, it has relatively high income level. However, despite the cotton boom, the region has not experienced any great poverty reduction since 1994. Mouhoun, another of the major cotton regions, has always had very high poverty levels. In contrast, the cotton region Cascades succeeded in lowering poverty by more than a third between 1994 and 2003 (poverty lines used to calculate the poverty headcount ratios are taken from Grimm and Günther (2007)).

\section{[insert Table 1]}

To see whether the observed pattern of economic growth and poverty reduction follows a similar pattern at the provincial level, i.e. to see whether provinces in a given region develop similarly, we further disaggregate the data according to Burkina Faso's 45 provinces. The results are presented using maps (Figures 1 - 4). These maps indicate three important aspects. First, economic growth does not occur on a large regional scale. Second, poverty is not highly concentrated in particular regions. Rather the intensity of growth and poverty varies across provinces over the whole country. Third, the composition of the group of provinces with the highest poverty incidence changes over time. Similar to what Benson et al. (2005) found for rural Malawi, there do not seem to be spatial poverty traps in Burkina Faso.

$$
\text { [insert Figures } 1-4]
$$

Hence, a crucial question is how these income disparities between households within spatial units and between households of different spatial units can be explained. What is the contribution of the variance in household characteristics and area-specific endowments, such as the level of public services, infrastructure 
and climate? What is the importance of the spatial clustering of households? Are the effects of relevant factors similar across spatial units or do they vary significantly across the country? Finding the answers to questions like these seems important in order for appropriately designing and targeting poverty alleviation strategies in Burkina Faso, but also more broadly in many other parts of Sub-Saharan Africa. The only study we have found that addressed a similar question for the case of Burkina Faso is Bigman et al. (2000). As in our study, the authors used a very detailed data set combining information from the household, village, district and provincial level and constructed a 'poverty map' at the level of villages. From that map the authors concluded - without, however, providing a decomposition in quantitative terms - that differences in the incidence of poverty among regions are due primarily to differences in agro-climatic conditions, whereas differences in the incidence of poverty among villages within the same region often reflect past policy choices that lead to differences in the quality of roads or public services.

\section{Data and Empirical Strategy}

\subsection{Data}

At present, Burkina Faso is organized in 13 administrative regions (of which each shares relatively homogenous agro-climatic conditions), 45 provinces and 425 communities. In rural areas, communities are identical with the clusters randomly drawn to collect the household survey data. In larger towns and cities, clusters refer to quarters (or neighbourhoods). Burkina Faso has 26 cities and towns (population $>5,000$ ) and roughly 8,300 villages. The spatial entities are hierarchically nested. However, the administrative organization of Burkina Faso has changed over time. For instance, in 1994, the country was organized in only 30 provinces (but 436 communities). Hence, community and province boundaries changed between 1994 and 2003. Moreover, specific communities did not necessarily belong to the same province in 1994 and in 2003. This is also the reason why time is not considered as an additional level in the hierarchy of our model, because this would require that the levels are consistent over time.

According to the most recent census in 2006 the urbanization rate was about 16 percent (share of the population living in urban areas) and the average population density 48.4 persons per $\mathrm{km}^{2}$. The two major cities are Ouagadougou, the capital, with a population of roughly 1.1 million and Bobo-Dioulasso with a population of about 0.4 million. The third city, Koudougou has a population of only 83,400 (statistics provided by the Institut National de la Statistique et de la Démographie (INSD), see http://www.insd.bf.) The variables we use have been collected from a large number of sources and at different levels of that organizational structure. However, it was very difficult to find and gain access to data on agro-climatic characteristics, infrastructure and public services and, if it existed, it was difficult to match these data to other sources. This is a problem in many of the least developed countries and may explain why only very few attempts have been made so far to analyze the effects of area-specific characteristics on households' standards of living. 
Household data is drawn from three nationwide representative household surveys, the Enquête Prioritaires (EP), conducted in 1994 (EP I), 1998 (EP II) and 2003 (EP III) covering around 8,500 different households in each year. These surveys were conducted by INSD with technical and financial support by the World Bank. These surveys contain relatively detailed information on household socio-demographic characteristics, education, employment, agricultural and non-agricultural activities as well as consumption, income and some assets. A detailed description of these data sets can be found in Grimm and Günther (2007).

Given the usual low quality of income data in poor rural settings, we use (the log of) household expenditure per capita as an indicator of households' living standards throughout the empirical part of our paper. Expenditures were deflated to the year 1994 and to the price level in Ouagadougou using appropriate price deflators. A critical issue in our study are the deflators used to correct for price differences across space. We use deflators constructed for Burkina Faso's 13 regions (based on price data collected on 37 regional markets) provided by the INSD for each survey year. The INSD does not provide deflators on a lower spatial level.

Community-level data were obtained in different ways. Although the abovementioned household surveys were not linked to any village survey (except in 1998), the questionnaires contain some questions on community-level variables, such as the time needed to reach the next primary and secondary school, the next health centre, the next road, market and the next drinking water point. In 1998 a specific community survey was added to the household survey which collected further community data for 325 of the 425 communities covered by the survey. Further community variables were constructed simply by aggregating household characteristics at the community level. However, a community panel cannot be set up because each survey year does not cover exactly the same communities.

Data on the size of agricultural production units, fertilizer use and the use of modern production technologies in agriculture are drawn from a yearly agricultural survey called Enquête Agricole. This survey is conducted by the Ministry of Agriculture in collaboration with INSD. Since the data set uses a different survey design than the EPs, we merged the information to the other data sources at the provincial level, the smallest common spatial unit. The average size of agricultural production units, fertilizer use and information about modern production technologies are therefore provincial averages.

Data on agro-climatic conditions, such as monthly rainfall for the period 1993-2006 at the provincial level, and monthly minimum and maximum temperatures at the regional level were obtained from the Directorate of Meteorology (Direction de la Météorologie).

Data on the provision of public services, infrastructure and population densities, also at the provincial level, were obtained from the Ministry of Infrastructure (Direction Génerale de l'Amenagement du Territoire). Note that we do not have any data on project aid; thus, the effect of aid will be in the unobservables.

To summarize, the data set we use is organized on four levels: the household, the community (cluster), the province and the region. Table 2 shows all used 
variables together with their means and their source.

[insert Table 2]

\subsection{Empirical Strategy}

We use a multilevel (also known as hierarchical or mixed) regression model to analyze the determinants and variance of income levels across spatial units. For a comprehensive overview of the statistical theory underlying multilevel modelling and of various illustrative applications, see, for example, Browne and Rasbash (2004), Goldstein (2003), Snijders and Bosker (1999), Hox (1995) and Bryk and Raundenbush (1992). Multilevel models are widely used in social science, sociology and health research to specify the effect of social context on individual level outcomes. We rely on a multilevel model, because it allows us (i) to combine nested data from different sources, (ii) to decompose variation across levels, and, (iii) to model the variation of returns to characteristics across spatial units.

We use an iterative procedure to estimate the sources of spatial inequality. We start with a multilevel random intercept model (M0) of household expenditure per capita that does not include any covariates. Then, we iteratively introduce household-level variables (M1), community variables (M2) and provincial and regional variables (M3) into the model. At each stage of our analysis, our main concern is twofold: (i) What are the key characteristics explaining per capita income disparities? and (ii) To what extent do these characteristics drive the spatial variation at each hierarchical level?

Moreover, in Section 4.5 we will further augment our multilevel model to allow coefficients of household characteristics to vary across communities and model the covariances of the random effects at the community level (M4). Investigating the variance of the random coefficients and the correlation between random intercepts and slopes allows us to answer the following questions: (i) Does area affect the relationship between household characteristics and income? and, if so, (ii) What are the underlying factors?

We estimate our model for three points in time (1994, 1998, 2003), which also allows us to explore changes over time of spatial inequality and its determinants. Our full four level random coefficient model reads:

$$
\begin{gathered}
Y_{i j k l}=\left(\gamma_{0000}+\sum_{p=1}^{P} \gamma_{p 000} X_{p i j k l}+\sum_{q=1}^{Q} \gamma_{0 q 00} C_{q j k l}+\sum_{r=1}^{R} \gamma_{00 r 0} P_{r k l}+\sum_{m=1}^{M} \gamma_{000 m} R_{m l}\right) \\
+\left(W_{l}+V_{k l}+U_{j k l}+\sum_{p=1}^{P} U_{p j k l} X_{p i j k l}+\varepsilon_{i j k l}\right)
\end{gathered}
$$

where the index $i$ stands for households, $j$ for communities, $k$ for provinces and $l$ for regions. $X, C, P$ and $R$ are vectors of household, community, provincial and regional characteristics, respectively. $W_{l}$ is the regional random intercept, $V_{k l}$ the provincial random intercept and $U_{j k l}$ the community random intercept. 
The $\gamma^{\prime} s$ are fixed coefficients, while $U_{p j k l}$ are community-level random effects. We use Stata's 'xtmixed' command for estimation. The distribution of the error terms is assumed to be Gaussian.

The contribution of the variance at each level to the total variance can be measured with the 'variance partition coefficient', $\rho$, or 'VPC' hereafter (see also Goldstein et al. (2002)). In random intercept models, the VPC measures the degree to which observations that belong to the same observation unit at a given hierarchical level, e.g. households within a given community, are related. For random intercept models the VPC is the same as the 'intra-class correlation coefficient' (ICC). Considering a four-level random intercept model, the decomposition of the variance by hierarchical level reads:

$\operatorname{var}\left(Y_{i j k l} \mid X_{i j k l}\right)=\operatorname{var}\left(W_{l}\right)+\operatorname{var}\left(V_{k l}\right)+\operatorname{var}\left(U_{j k l}\right)+\operatorname{var}\left(\varepsilon_{i j k l}\right)=\sigma_{w}^{2}+\sigma_{v}^{2}+\sigma_{u}^{2}+\sigma_{\varepsilon}^{2}$.

Accordingly, the VPC, for the community level for instance, can be written as

$$
\rho_{C}=\frac{\sigma_{u}^{2}}{\sigma_{u}^{2}+\sigma_{v}^{2}+\sigma_{w}^{2}+\sigma_{\varepsilon}^{2}} .
$$

Since a multilevel model implicitly assumes errors to be independently distributed across levels, the total variance of the dependent variable can be decomposed into the variances at each level. Note also that equation 2 is based on a random intercept model, while we present the full random coefficient model in equation 1 . We do not present the variance decomposition based on the full random coefficient model since we do not calculate the VPC for any random coefficient model.

The decomposition of the error term allows us at each hierarchical level to estimate the shares of the variance that can be explained by level-specific observable characteristics and by systematic sorting of observable lower-level characteristics at that level. For instance, the variance in households' living standards between communities might be driven by the variance in community-specific endowments and by a sorting of households with favourable and unfavourable characteristics across communities. In sum, our approach allows us to answer the following questions: (i) How much of the total variance in incomes between households is attributable to differences between communities? (ii) How much of the variance between communities can be explained by differences in observed household characteristics between these communities? and (iii) How much of the variance between communities can be explained by differences in observed community characteristics? While question (i) can be answered by looking at the VPC (equation 3), (ii) and (iii) can be answered by calculating the proportional change of the variance components when sequentially introducing the regressors (Model M1 to M3). Yet, there are a few caveats inherent in this approach that have to be kept in mind. First, there may also be sorting on unobserved characteristics. In that case, variation attributed to higher-level characteristics would also include variation due to this 'unobserved sorting'. Additionally, characteristics at the lower level may, in the first place, be driven by higher-level factors. 
In order to answer question (ii) we have to estimate the proportional change of the variance component observed at the community level when introducing household variables. This change is given by

$$
\Delta \sigma_{u_{H} H}=\frac{\sigma_{u_{M_{0}}}^{2}-\sigma_{u_{M_{1}}}^{2}}{\sigma_{u_{M_{0}}}^{2}} .
$$

Correspondingly, to answer question (iii), we need to estimate the proportional change of the variance component observed at the community level when introducing community variables. This change is given by

$$
\Delta \sigma_{u_{C}}=\frac{\sigma_{u_{M_{1}}}^{2}-\sigma_{u_{M_{2}}}^{2}}{\sigma_{u_{M_{0}}}^{2}} .
$$

We believe that a multilevel model of the type presented here is particularly suitable for decomposing inequality across and between spatial units. Our approach allows the decomposition of spatial inequality into the contribution of observed household and area-specific characteristics, to identify the key spatial determinants of inequality and to track variations in returns across space. Thus our approach also preserves most of the advantages of the methods used by Ravallion and Wodon (1999), Jalan and Ravallion (2002) and Benson et al. (2005).

Ravallion and Wodon (1999) developed the spatial analogue of the OaxacaBlinder decomposition (Oaxaca 1973). The latter is a simple tool based on linear regression analysis where the difference between two outcomes (e.g. the wage differential between men and women) is decomposed into differences in characteristics and differences in returns to those characteristics. Our approach complements this idea by allowing us to estimate the relative magnitudes of the contributions of the different components. Moreover, our approach goes beyond the identification of the effects of higher-level variables on household income, which is done in Jalan and Ravallion (2002) using a generalized method of moments (GMM) estimator. In principle, it also differentiates between significant higher-level effects that represent higher-level inequality and significant higherlevel effects that just pick up omitted household characteristics clustered at the higher level.

Obviously, our approach also has some drawbacks. In the absence of panel data, we cannot exclude the possibility that there are endogeneity problems with some of our explanatory variables. A more general criticism is that multilevel models bear the risk of inconsistent fixed effects parameter estimation, because multilevel modelling only controls for unobserved heterogeneity as long as the independence assumption between unobserved characteristics and the fixed effects holds. In other words, multilevel models assume area effects to be independent of the covariates and any unobserved individual effects. Given that we focus primarily on the variance partitioning, we do not consider this as a major problem. Moreover, we introduce a large set of control variables which should largely reduce the unobserved heterogeneity bias. 


\section{Results: Sources of Spatial Inequality}

\subsection{Model M0: The null model}

We begin by estimating for each year a four-level null model where we introduce nothing but a random intercept at the community, the provincial and the regional levels. Using a likelihood ratio test, we check whether the three-level models, nested in the four-level model, perform better than the four-level model (see Goldstein (2003)), i.e. we compare three different three-level models with the four-level model; one excluding the regional level, one excluding the provincial level and one excluding the community level. We find significant variation at each level and for each of the three years under consideration. This result suggests that there exists significant inequality in income at all levels. In other words, living standards do not only vary significantly between households, but also between communities, provinces and regions. Hence, we use a four-level model below. Fixed effect estimates for the models are given separately for each year in Tables 3 - 5 and variance and covariance estimates for the random effects at different levels are given in Tables $6-8$.

$$
\text { [insert Tables } 3-8 \text { ] }
$$

The VPC $(\rho)$ for every year is shown in Table 9. The high VPC at the community level $\left(\rho_{c}\right)$ points to two aspects: (i) it underlines the importance of using a multilevel approach to obtain efficient estimates, and (ii) it suggests large community effects which are relatively stable over time (1994: 21.9 percent; 1998: 26.5 percent; 2003: 20.5 percent). The very small contribution of the provincial level, in particular, in comparison to the regional level, can be explained by the fact that in Burkina Faso regions rather than provinces follow agro-climatic zones.

[insert Table 9]

Again, the finding that a significant share of the variance in income measured at the household level is due to the variance at higher levels does not necessarily result from heterogeneity in higher-level characteristics. Differences between communities can result from a systematic sorting of household characteristics across communities, i.e. similar households are spatially concentrated. To see whether this is the case, we have to estimate the proportional change in the random intercepts after accounting for household characteristics, i.e. we have to control for systematic differences in household characteristics at higher levels. It should be noted that household characteristics can lie in the causal pathway between area characteristics and household income; for example, better and more schools may lead to better education outcomes. Hence, the inclusion of household characteristics may tend to lead to an understatement of the importance of area characteristics. 


\subsection{Model M1: The role of household characteristics}

Now we add household characteristics as explanatory variables to the random intercept model. We call this model 'M1'. We use maximum likelihood techniques for estimation, and rely on the Akaike Information Criterion (AIC) to select the best model. We estimated other versions of M1 with a larger set of explanatory variables, but present here only those models with the lowest AIC and exclude explanatory variables that were not significant. All variables presented in Table 2 were tested.

\subsubsection{Key household-level characteristics}

All household variables have the expected sign and are in line with our expectations. In particular, household composition has a considerable effect on income levels. In terms of per capita incomes, smaller households are significantly better off in all years under consideration. The household's age structure, which is measured through a set of dependency ratios, also has a significant effect. While the number of children per adult lowers per capita income in all three years we consider, the number of older persons per adult in the household is insignificant in 1994 and 2003 (thus dropped from the regression for these years), but significant and negative in 1998 .

Age of the household head has a significant negative effect on household income in all years. The level of formal education also matters. Households with a literate head and with a higher percentage of literate adults have, on average, a higher household income. Belonging to the largest and politically dominant ethnicity of the country, the Mossi, which represents roughly 50 percent of the population, has no influence on household income, however (the second largest ethnic group - the Peulh - represents less than 10 percent of the population only). Religion has a weak effect in a sense that belonging to one of the two large religious groups in Burkina Faso-Islam (55 percent) and Christianity (22 percent) - has a positive, but only barely significant effect on income.

The effect of cotton farming differs across periods. Cotton farmers were better off in 1998 and 2003. However, in 1994 cotton farmers were not yet significantly richer than food crop farmers. This is plausible, since the 'cotton boom' set in after the devaluation of the CFA Franc in January 1994, and was enhanced afterwards by a very favourable evolution of the world market price for cotton. It was also accompanied by a substantial expansion of land used for cotton cultivation. Moreover, it is interesting to see that farmers that were also engaged in livestock herding, which is often done to diversify risk, were significantly better off in 2003. In the next section, we will analyze whether household characteristics are systematically distributed between communities, provinces and regions.

\subsubsection{Contribution of household characteristics to spatial variation}

For all years the community and regional variance components decline after the incorporation of household-level characteristics. For the provincial component 
the direction of the change is different for the various years, which is not surprising given the small size and low significance of the provincial random intercept. The proportional changes of the community and regional variance components are surprisingly stable across survey years (see Tables $6-8$ and Table 9 ). Controlling for household-level characteristics reduces the community variance and the regional variance component by around 50 percent.

The results indicate that 50 percent of the variance in income at the community and regional levels can be explained by a systematic distribution of household characteristics across communities and regions. The remaining unexplained variation could be due to unobserved household or observed and unobserved community and region-specific characteristics. Hence, testing the explanatory power of higher-level characteristics is essential. That is what we do next.

\subsection{Model M2: The role of community characteristics}

We start by estimating the proportional change in the variance components after incorporation of community characteristics (Model M2). Again, we use the AIC as a model selection criterion and present only the best-fitting of the M2 models. All community variables that were tested for significance are listed in Table 2.

\subsubsection{Key community-level characteristics}

As can be seen in Tables 3 - 5, communities that are more urbanized, that have access to electricity (we do not have a variable indicating whether a community is connected to the grid, hence we use as a proxy whether at least one household in the community had access), that have a higher share of literate household heads and adults, and that have a higher ethnic fragmentation are better off (ethnic and religious fragmentation are measured based on a fractionalization index (see Table 2)). The education effects are particularly interesting, because they suggest that the social returns exceed the private returns due to positive spill-over effects between low and high education groups. Most other community averages of household-level characteristics turn out to be insignificant. This is also true of the percentage of cotton farmers in a community, which suggests the absence of any substantial forward and backward linkages between cotton farming households and other households. This is a sign of a high product and factor market segmentation, which is typical of a poor, largely agricultural economy. Finally, once we control for literacy among the adult population, access to primary and secondary schools, as measured by the time needed to reach these schools, does not turn out to be significant.

Regarding the positive electricity effect that we find, it is important to emphasize that we cannot be sure that this effect is causal. Electricity may predominantly exist in areas where people can afford it. In this case, income is causing the availability of electricity and not the other way around. Moreover, it is important to emphasize that this correlation may imply a broader infrastructure effect. Power transmission lines are usually found along gravel or paved 
roads, hence the measured effect may include the effect associated with access to roads. We do not find significant effects associated with access to health centres and access to markets, once we control for the degree of urbanization. They are significant, though, in a regression where urbanization is excluded from the list of regressors. However, the same remark as before concerning causality applies.

As mentioned in Section 3, in 1998 the household survey was accompanied by a community survey covering 325 out of the 425 clusters. This much richer community-level dataset can thus only be examined at the cost of losing one quarter of all households in the sample. Hence, we report regression results using that additional data separately in model $\mathrm{M}^{*}$ shown in Table 4 . Of all variables collected in the community survey (see Table 2), only access to a road and to a hospital as well as malaria prevalence are significantly correlated with household income. Signs are as expected in each case and, hence, the results suggest that health-related factors are important correlates of income differences across villages.

\subsubsection{Contribution of community characteristics to spatial variation}

After the inclusion of the community factors, the variance at the community level is significantly reduced in all three years (see Tables 6 - 8 and Table 9). Controlling for household characteristics, between 20 and 30 percent of the variance in income between communities is explained by our set of observed community factors. Thus, the structure of agricultural production, average education, urbanization, access to basic health and education services and electricity seem to cover a large set of relevant factors and can explain a major part of the variance in income between communities.

Now, we can also estimate to what extent community-level variables give rise to income differences between provinces and regions. The results are shown in Table 9 . We see that in 1994 around 36 percent of the variance in income at the regional level can be explained by differences in observed community endowments. The shares are 28 percent and 16 percent in 1998 and 2003, respectively. However, here again, we cannot, of course, rule out the possibility that factors at the provincial or regional level affect factors at the community level. Hence, this kind of decomposition does not allow to make a statement about what exactly gives rise to the differences in community endowments within a province or a region.

\subsection{Model M3: The role of provincial and regional characteristics}

In a next step, we include provincial and regional-level variables in Model M3. However, it turns out that all provincial and regional-level variables except the 1998 rainfall variable (the drought year) are insignificant. Population density, the density of paved and gravelled roads, the average maximum temperature and the variation of rainfall do not have a significant effect once household and community-level characteristics are included. The remaining unexplained variation could not be lowered in any of the three years under consideration. 
Table 9 summarizes the contribution of observed and unobserved characteristics to the total variance in income and the variance in income at each single spatial level.

This result of relatively unimportant 'macro-level' variables is consistent with findings by other authors. Jalan and Ravallion (2002) and Benson et al. (2005), for instance, did not find a significant effect of population density on household income, either. The results by Benson et al. (2005) confirm our result of a missing effect of access to roads. Jacoby (2000) also concluded that the response of poverty to infrastructure is often quite weak (although we do find a significant effect when using the sub-sample of households covered by the community survey in 1998). Generally, Burkinabè households seem to cope quite well with rainfall fluctuations. However, the occurrence of substantial shocks, such as a severe drought, like the one in 1997/98, or an unusual distribution of rainfall over the year like in 2006/07, are not without impact on household incomes, as is revealed by the significant positive rainfall coefficient in the drought year 1998. In line with this finding, Benson et al. (2005) found that in Malawi the effect of rainfall quantity on income was only significant when it is exceptionally high or low. Dercon (2004) confirms this finding for Ethiopia too. In Ethiopia only severe droughts had an impact on household income.

Our results also confirm those by Bigman et al. (2000). They concluded that disparities between regions in Burkina Faso are driven by agro-climatic conditions, whereas disparities between villages are driven by differences in infrastructure. We stress the importance of community characteristics, including infrastructure even more than they do. Our analysis suggests that a large part of regional disparity is actually also driven by differences in community charac-

teristics between these regions. Hence, we conclude that the actual impact of agro-climatic conditions is even lower than suggested by Bigman et al. (2000).

\subsection{Model M4: Variations in household-level effects across communities}

Now, we allow household-level effects to differ across communities. Hence, we add random coefficients (see equation 1) to the random intercepts at the community level. Covariances of random effects are modeled unstructured, i.e. all variances and covariances are distinctly estimated. We use an iterative procedure to test for significant variances and covariances of all significant household-level variables included in model M2. We use likelihood-ratio tests by estimating the likelihood deviance for the model without the specific random effect and for the model with the specific random effect. We keep only those random effects in model M4 for which the test-statistic - the difference between the deviances of the two models - is significant, i.e. if we obtain a $\chi^{2}$ with an associated $p$-value below 5 percent in a one-tailed test (Goldstein 2003). In addition, variances and covariances are considered as insignificant when their standard error is larger than their estimate (Tseloni 2006).

We obtain relatively homogenous results over the three survey years (see Tables 6 - 8). Effects associated with education, household size and household composition vary significantly between communities. In contrast, effects 
associated with age and gender of the household head, cotton farming and livestock herding do not. The variation of returns across communities is not only statistically significant but also economically meaningful. The fixed effect estimate of the variable 'literate head' of 0.26 in 1994 implies that households with a literate head have on average, a per capita income that is 26 percent higher than that of households with an illiterate head. The variance of the random effect states, however, that this return differs significantly between communities. For instance, for 1994 the effect varies from minus 20 percent $((.26-1.96 * \sqrt{.055}) * 100)$ to plus 72 percent $((.26+1.96 * \sqrt{.055}) * 100)$ between the 2.5th and 97.5th centile of Burkinabè communities (see also Tseloni and Pease (2004)). Similar variations are stated for 1998 and 2003. This again suggests that labour markets are segmented and not competitive, since returns are not equated across communities.

To see whether the heterogeneity in returns is driven by regional, in particular agro-climatic, factors, we compute the best linear unbiased predictors (BLUP) of the community random effects and check whether these systematically differ between the 13 agro-climatic regions in Burkina Faso. We do not find a systematic north-south or east-west pattern in returns to education across the 13 regions in any of the three years. The same is true of the effects associated with household size and composition. This suggests that the heterogeneity of effects across communities is driven by the community characteristics themselves and not by any regional factor.

Finally, we can examine the covariance of random effects and random intercepts. For the returns to education the covariance between the random effect and the random community intercept turns out to be significantly positive in 1998 and 2003. This means that, on average, returns to education are higher in communities with a higher income and suggests that these communities offer more skill-intensive jobs in the modern sector or use more modern technology in agriculture, such as irrigation systems, pesticides, fertilizer and improved seeds, which typically require a skilled agricultural workforce. Given the positive correlation between the mean incomes of literate and illiterate household heads across communities, the result implies also that as the income of one group increases, that of the other will also increase.

\section{Conclusion}

We decomposed income inequality in Burkina Faso into contributions from various nested levels: the household, the community, the province and the region. We found that about 60 percent of the total variance in incomes stems from variance between households, 20 percent from the variance between communities, less than 5 percent from the variance between provinces and about 10 percent from the variance between (agro-climatic) regions. We also found that at each level not only household, but also community characteristics play an important role. The results are consistent with the hypothesis that communities are poor not only because the households living there have characteristics which make them poor, but also because these communities are geographically 
disadvantaged, provide fewer public services and offer only limited access to markets and infrastructure. These characteristics explain a substantial part of the variance in incomes after household characteristics are controlled for, although causality cannot be established with the data at hand. Differences between regions, the largest spatial unit we considered, are largely driven by differences between communities. Once we control for community characteristics, factors such as rainfall, temperature or the existence and quality of roads that do not vary much within regions explain almost nothing in the variance of incomes between regions. We also found robust evidence that returns to some of the relevant community factors, such as average education, vary significantly across communities.

Although one has to be careful in drawing direct policy implications from this analysis, we think a few lessons can be learnt. The fact that many communities are better off than others points to small growth poles that are, however, only weakly connected and, therefore, do not yet generate the necessary positive spill-overs on other communities. This is a clear sign of market segmentation typical of many poor and largely rural economies. Given this finding, it would be worth assessing the potential effects of policies which build and enhance infrastructure that connects communities (e.g. road, railway, communication) complemented by interventions targeted to specific villages that particularly lag behind, e.g. via fiscal incentives for manufacturing firms, the construction of schools and health centres and the provision of agricultural extension services, i.e. programmes that train farmers in using new production technologies, such as high yield varieties, fertilizer and irrigation. At the national level, this process should be accompanied by continuous improvements in the quality of institutions necessary to implement and sustain such policies over time. In that sense our study strongly supports one of the main conclusions of the World Development Report 2009 (World Bank 2008), which states that 'economic integration is the most promising way to achieve convergence in living standards in countries that are characterized by a very uneven distribution of resources across space'. The targeting of specific communities to accompany the process of integration may in some cases be politically difficult, which suggests that economy-wide improvements in the quality of institutions are even more important as such improvements may make interventions of this kind more likely.

\section{References}

Anselin, L., Florax, R. J., and Rey, S. J. (2004), Advances in Spatial Econometrics: Methodology, Tools and Applications, Berlin: Springer-Verlag.

Benson, T., Chamberlin, J., and Rhinehart, I. (2005), "An Investigation of the Spatial Determinants of the Local Prevalence of Poverty in Rural Malawi," Food Policy, 30, 532-550.

Besley, T. and Cord, L. (2007), Delivering on the Promise of Pro-Poor Growth: Insights and Lessons from Country Experiences, New York: Palgrave Macmillan. 
Bigman, D., Dercon, S., Guillaume, D., and Lambotte, M. (2000), "Community Targeting for Poverty Reduction in Burkina Faso," World Bank Economic Review, 14, 167-193.

Browne, W. J. and Rasbash, J. (2004), "Multilevel Modelling," in Handbook of Data Analysis, eds. Bryman, A. and Hardy, M., London: Sage Publications, pp. $459-479$.

Bryk, A. and Raundenbush, S. (1992), Hierarchical Linear Models: Applications and Data Analysis Methods, Newbury Park, NJ: Sage.

De Vreyer, P., Herrera, J., and Mesplé-Somps, S. (2009), "Consumption Growth and Spatial Poverty Traps: An Analysis of the Effect of Social Services and Community Infrastructures on Living Standards in Rural Peru," in Poverty, Inequality, and Policy in Latin America, eds. Nowak-Lehmann, F. and Klasen, S., MIT Press, pp. 129-156.

Dercon, S. (2004), "Growth and Shocks: Evidence from rural Ethopia," Journal of Development Economics, 74, 309-329.

Durlauf, S. (1994), "Spillovers, Stratification and Inequality," European Economic Review, 38, 836-845.

Ecob, R. (1996), "A Multilevel Modelling Approach to Examining the Effects of Area of Residence on Health and Functioning," Journal of the Royal Statistical Society Series A, 159, 61-75.

Goldstein, H. (2003), Multilevel Statistical Models, vol. 3, London: Edward Arnold.

Goldstein, H., Browne, W., and Rasbash, J. (2002), "Partitioning Variation in Multilevel Models," Understanding Statistics, 1, 223-231.

Grimm, M. and Günther, I. (2007), "Growth and Poverty in Burkina Faso. A Reassessment of the Paradox," Journal of African Economies, 16, 70-101.

Grimm, M., McKay, A., and Klasen, S. (2007), Determinants of Pro-Poor Growth: Analytical Issues and Findings from Country Cases, London: Palgrave-Macmillan.

Hox, J. J. (1995), Applied Multilevel Analysis, Amsterdam: TT-Publikaties.

IMF (2003), Burkina Faso: IMF Country Report No. 03/197.

Jacoby, H. G. (2000), "Access to Markets and the Benefits of Rural Roads," The Economic Journal, 110, 713-737.

Jalan, J. and Ravallion, M. (2002), "Geographic Poverty Traps? A Micro Model of Consumption Growth in Rural China," Journal of Applied Econometrics, $17,329-346$. 
McKay, A. (2007), "Introduction to Methods for Analysing the Distributional Pattern of Growth," in Determinants of Pro-Poor Growth: Analytical Issues and Findings from Country Cases, eds. Grimm, M., McKay, A., and Klasen, S., London: Palgrave-Macmillan, pp. 135-163.

Merlo, J., Chaix, B., Yang, M., Lynch, J., and Rastam, L. (2005), "A Brief Conceptual Tutorial on Multilevel Analysis in Social Epidemiology: Investigating Contextual Phenomena in Different Groups of People," Journal Epidemiol. Community Health, 59, 729-736.

Oaxaca, R. L. (1973), "Male-Female Wage Differentials in Urban Labor Markets," International Economic Review, 14, 693-709.

Ravallion, M. and Wodon, Q. (1999), "Poor Areas, or Only Poor People?" Journal of Regional Science, 39, 689-711.

Snijders, T. A. and Bosker, R. J. (1999), Multilevel Analysis: An Introduction to Basic and Advanced Multilevel Modeling, London: Sage.

Tseloni, A. (2006), "Multilevel Modelling of the Number of Property Crimes: Household and Area Effects," Journal of the Royal Statistical Society A, 169, 205-233.

Tseloni, A. and Pease, K. (2004), "Repeat Personal Victimization: Random Effects, Event Dependence and Unexplained Heterogeneity," The British Journal of Criminology, 44, 934-945.

UNDP (2009), Human Development Report 2009. Overcoming barriers. Human mobility and development, United Nations Development Programme, New York (Published by Palgrave Macmillan).

World Bank (2008), World Development Report 2009: Reshaping Economic Geography. 
Table 1: Regional Growth and Poverty Statistics

\begin{tabular}{|c|c|c|c|c|c|c|c|c|c|c|c|c|c|}
\hline & \multicolumn{3}{|c|}{1994} & \multicolumn{3}{|c|}{1998} & \multicolumn{3}{|c|}{2003} & \multicolumn{3}{|c|}{ Growth ${ }^{\dagger \dagger \dagger}$} & \multirow{2}{*}{$\begin{array}{c}\text { Change in P0 } \\
94-03 \\
\text { (\%points) }\end{array}$} \\
\hline & $\begin{array}{l}\text { Pop.- } \\
\text { share }\end{array}$ & $\begin{array}{c}\text { PC Expen- } \\
\text { diture }^{\dagger}\end{array}$ & $\mathrm{P} 0^{\dagger \dagger}$ & $\begin{array}{l}\text { Pop.- } \\
\text { share }\end{array}$ & $\begin{array}{c}\text { PC Expen- } \\
\text { diture }\end{array}$ & $\mathrm{P} 0$ & $\begin{array}{l}\text { Pop.- } \\
\text { share }\end{array}$ & $\begin{array}{l}\text { PC Expen- } \\
\text { diture }\end{array}$ & $\mathrm{P} 0$ & $94-98$ & 98-03 & $94-03$ & \\
\hline Burkina Faso & 100 & 100 & 55.5 & 100 & 82 & 61.8 & 100 & 108 & 47.2 & $-17.5 \%$ & $31.5 \%$ & $8.5 \%$ & -8.3 \\
\hline Eastern regions & 32.9 & 69.3 & 68.4 & 23.9 & 70.9 & 72.2 & 22.6 & 89.2 & 46.9 & $2.4 \%$ & $25.7 \%$ & $28.6 \%$ & -21.5 \\
\hline Sahel & 5.5 & 74.2 & 62.9 & 6.4 & 67.5 & 59.3 & 5.8 & 124.6 & 36.9 & $-9.0 \%$ & $84.5 \%$ & $67.9 \%$ & -26.0 \\
\hline Est & 8.8 & 81.1 & 64.5 & 8.6 & 63.4 & 66.7 & 8.5 & 100.6 & 42.1 & $-21.9 \%$ & $58.7 \%$ & $24.0 \%$ & -22.5 \\
\hline Centre-nord & 8.8 & 69.7 & 65.0 & 8.9 & 51.2 & 78.4 & 8.3 & 104.8 & 36.0 & $-26.6 \%$ & $104.7 \%$ & $50.3 \%$ & -29.0 \\
\hline Nord & 9.8 & 55.6 & 78.1 & 9.6 & 54.8 & 79.9 & 8.6 & 66.2 & 69.0 & $-1.4 \%$ & $20.8 \%$ & $19.1 \%$ & -9.1 \\
\hline Western regions & 20.5 & 89.7 & 51.8 & 21.5 & 89.0 & 59.1 & 22.8 & 82.6 & 51.7 & $-0.7 \%$ & $-7.2 \%$ & $-7.9 \%$ & -0.1 \\
\hline Cascades & 2.2 & 85.4 & 58.3 & 3.0 & 94.6 & 48.2 & 3.6 & 124.3 & 38.4 & $10.7 \%$ & $31.4 \%$ & $45.5 \%$ & -20.0 \\
\hline Hauts Bassins* & 8.1 & 95.1 & 40.2 & 8.0 & 75.7 & 54.8 & 6.9 & 105.2 & 41.4 & $-20.5 \%$ & $39.0 \%$ & $10.5 \%$ & 1.3 \\
\hline Mouhoun & 10.2 & 86.2 & 59.5 & 10.6 & 65.7 & 65.5 & 12.2 & 70.4 & 61.5 & $-23.8 \%$ & $7.1 \%$ & $-18.4 \%$ & 2.0 \\
\hline Cenral regions & 35.1 & 86.4 & 60.5 & 44.5 & 81.8 & 65.2 & 42.5 & 79.2 & 55.5 & $-5.4 \%$ & $-3.2 \%$ & $-8.4 \%$ & -5.0 \\
\hline Sud-ouest & 4.9 & 108.7 & 54.1 & 4.2 & 62.0 & 64.2 & 4.9 & 75.9 & 57.9 & $-43.0 \%$ & $22.3 \%$ & $-30.2 \%$ & 3.8 \\
\hline Centre-ouest & 10.2 & 90.2 & 61.9 & 10.7 & 76.1 & 61.8 & 8.6 & 108.8 & 42.1 & $-15.6 \%$ & $42.9 \%$ & $20.6 \%$ & -19.8 \\
\hline Plateau & 5.0 & 78.6 & 63.3 & 5.6 & 56.9 & 67.7 & 6.1 & 78.3 & 60.5 & $-27.7 \%$ & $37.6 \%$ & $-0.5 \%$ & -2.7 \\
\hline Centre-est & 8.0 & 81.3 & 57.4 & 8.0 & 71.2 & 70.3 & 8.3 & 88.3 & 56.3 & $-12.5 \%$ & $24.0 \%$ & $8.5 \%$ & -1.1 \\
\hline Centre ${ }^{* *}$ & 2.0 & 67.4 & 63.5 & 2.0 & 73.8 & 52.3 & 1.8 & 68.8 & 66.5 & $9.5 \%$ & $-6.8 \%$ & $2.0 \%$ & 2.9 \\
\hline Centre-sud & 5.0 & 80.2 & 64.6 & 4.4 & 55.4 & 67.3 & 4.3 & 65.1 & 65.9 & $-31.0 \%$ & $17.6 \%$ & $-18.8 \%$ & 1.3 \\
\hline Urban Centers & 11.6 & 246.7 & 10.4 & 10.1 & 282.4 & 21.7 & 12.2 & 218.4 & 16.4 & $14.5 \%$ & $-22.7 \%$ & $-11.5 \%$ & 6.0 \\
\hline Ougadougou & 8.2 & 258.8 & 8.4 & 7.3 & 255.6 & 20.5 & 8.3 & 270.2 & 13.6 & $-1.2 \%$ & $5.7 \%$ & $4.4 \%$ & 5.2 \\
\hline Bobo & 3.4 & 217.8 & 15.0 & 2.8 & 173.9 & 24.7 & 3.8 & 164.2 & 22.4 & $-20.2 \%$ & $-5.6 \%$ & $-24.6 \%$ & 7.3 \\
\hline
\end{tabular}

Source: Enquête Prioritaires I (EP I), Enquête Prioritaires II (EP II), Enqête Prioritaires III (EP III), estimations by the authors.

$\dagger$ Normalized per capita expenditure (total Burkina Faso $1994=100$ ).

t† Poverty headcount ratio, i.e. the share of the population below the poverty line in respective region.

${ }^{\dagger \dagger}$ Growth is the relative change in household expenditure per capita between respective years.

* Without Bobo-Diolassou; ** Without Ouagadougou. 

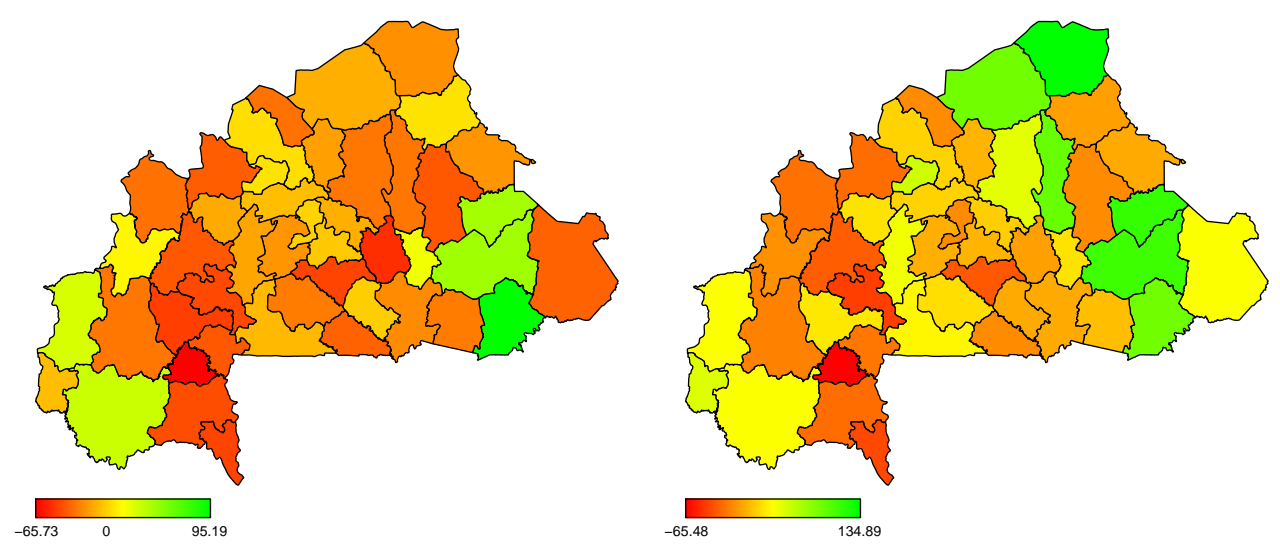

Figure 3: Poverty Incidence (P0) 1994 Figure 4: Poverty Incidence (P0) 2003
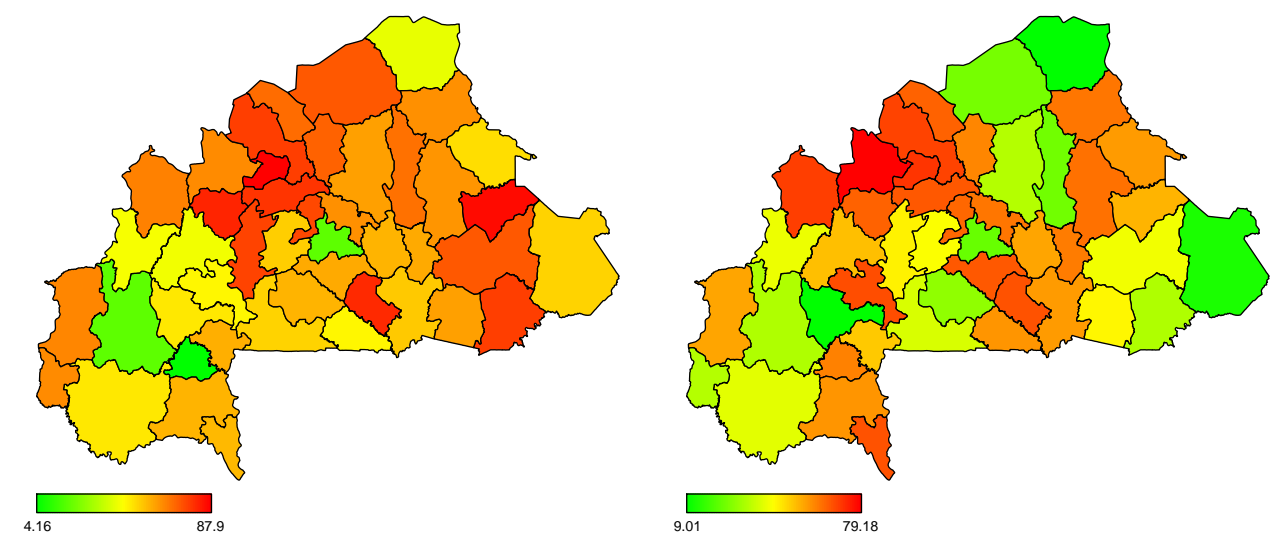

Source: EP I, EP II, EP III, estimations by the authors.

Growth refers to the percentage change in household expenditure per capita between the two years. 
Table 2: Potential Determinants of Spatial Inequality-Descriptive Statistics of Variables

\begin{tabular}{|c|c|c|c|c|c|c|c|c|}
\hline \multirow[t]{2}{*}{ Name } & \multirow[t]{2}{*}{ Label } & \multicolumn{2}{|c|}{1994} & \multicolumn{2}{|c|}{ 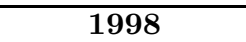 } & \multicolumn{2}{|c|}{2003} & \multirow[t]{2}{*}{ Source } \\
\hline & & Mean & Std dev & Mean & Std dev & Mean & Std dev & \\
\hline \multicolumn{9}{|l|}{ Household level } \\
\hline HH Size & Household size & 7.53 & 5.50 & 7.50 & 5.18 & 6.36 & 4.07 & Enq. Prioritaire \\
\hline Child Adult & Children (0-6) per adult & 0.54 & 0.51 & 0.50 & 0.49 & 0.49 & 0.48 & Enq. Prioritaire \\
\hline Youth Adult & Youth (7-14) per adult & 0.51 & 0.54 & 0.51 & 0.55 & 0.47 & 0.54 & Enq. Prioritaire \\
\hline Elderly Adult & Elderly $(55+)$ per adult & 0.13 & 0.30 & 0.13 & 0.30 & 0.12 & 0.30 & Enq. Prioritaire \\
\hline Age & Age of HH head & 45.79 & 15.21 & 46.08 & 15.01 & 44.23 & 15.17 & Enq. Prioritaire \\
\hline Sex & $\mathrm{HH}$ head is male & $91 \%$ & & $91 \%$ & & $91 \%$ & & Enq. Prioritaire \\
\hline Literate Head & HH head is literate & $25 \%$ & & $24 \%$ & & $26 \%$ & & Enq. Prioritaire \\
\hline Literate Adult & $\%$ of literate adults in $\mathrm{HH}$ & $36 \%$ & & $33 \%$ & & $37 \%$ & & Enq. Prioritaire \\
\hline Cotton & $\mathrm{HH}$ primarily engaged in cotton farming & $6 \%$ & & $12 \%$ & & $13 \%$ & & Enq. Prioritaire \\
\hline Livestock & $\mathrm{HH}$ engaged in some livestock herding & $56 \%$ & & $63 \%$ & & $65 \%$ & & Enq. Prioritaire \\
\hline Muslim & $\mathrm{HH}$ head is Muslim & $58 \%$ & & $54 \%$ & & & & Enq. Prioritaire \\
\hline Christian & HH head is Christian & $24 \%$ & & $25 \%$ & & & & Enq. Prioritaire \\
\hline Mossi & HH head is Mossi & $49 \%$ & & $50 \%$ & & & & Enq. Prioritaire \\
\hline \multicolumn{9}{|l|}{ Community level } \\
\hline $\mathrm{ZD}^{*} \mathrm{HH}$ size & Avg HH size in community & 7.53 & 2.19 & 7.51 & 2.39 & 6.36 & 1.56 & Enq. Prioritaire \\
\hline ZD Child Adult & Avg number of childr. per adult & 0.54 & 0.17 & 0.50 & 0.17 & 0.49 & 0.17 & Enq. Prioritaire \\
\hline ZD Youth Adult & Avg number of youth per adult & 0.51 & 0.16 & 0.51 & 0.17 & 0.47 & 0.16 & Enq. Prioritaire \\
\hline ZD Elderly Adult & Avg number of elderly per adult & 0.13 & 0.09 & 0.13 & 0.10 & 0.12 & 0.08 & Enq. Prioritaire \\
\hline ZD Religion & Religious fragmentation in community** & 0.36 & 0.23 & 0.39 & 0.22 & & & Enq. Prioritaire \\
\hline ZD Ethnicity & Ethnic fragmentation in community** & 0.28 & 0.26 & 0.30 & 0.25 & & & Enq. Prioritaire \\
\hline Next Road & Distance to next road in $\mathrm{km}$ & & & 9.30 & 13.52 & & & Enq. Communit. \\
\hline Next Tarred Road & Distance to next tarred road in $\mathrm{km}$ & & & 79.50 & 87.67 & & & Enq. Communit. \\
\hline Next Market & Distance to next road in $\mathrm{km}$ & & & 3.72 & 6.02 & & & Enq. Communit. \\
\hline Next Hospital & Distance to next hospital in $\mathrm{km}$ & & & 6.84 & 7.36 & & & Enq. Communit. \\
\hline Next Pharmacy & Distance to next pharmacy in $\mathrm{km}$ & & & 8.07 & 9.18 & & & Enq. Communit. \\
\hline ZD Cotton & $\%$ of HHs primarily engaged in cotton & $6 \%$ & & $12 \%$ & & $13 \%$ & & Enq. Prioritaire \\
\hline ZD Livestock & $\%$ of HHs engaged in some livestock & $56 \%$ & & $63 \%$ & & $65 \%$ & & Enq. Prioritaire \\
\hline
\end{tabular}




\begin{tabular}{|c|c|c|c|c|c|c|c|c|}
\hline \multirow[t]{2}{*}{ Name } & \multirow[t]{2}{*}{ Label } & \multicolumn{2}{|c|}{1994} & \multicolumn{2}{|c|}{1998} & \multicolumn{2}{|c|}{2003} & \multirow[t]{2}{*}{ Source } \\
\hline & & Mean & Std dev & Mean & Std dev & Mean & Std dev & \\
\hline ZD Literate & $\%$ of literate adults in community & $36 \%$ & & $33 \%$ & & $37 \%$ & & Enq. Prioritaire \\
\hline ZD Literate Head & $\%$ of literate $\mathrm{HH}$ heads in community & $25 \%$ & & $24 \%$ & & $26 \%$ & & Enq. Prioritaire \\
\hline Electricity & $1 \mathrm{HH}$ in community has electr. & $24 \%$ & & $28 \%$ & & $32 \%$ & & Enq. Prioritaire \\
\hline Urban & Urban community & $32 \%$ & & $31 \%$ & & $31 \%$ & & Enq. Prioritaire \\
\hline Primary Access & Next primary school within $30 \mathrm{~min}$ & $92 \%$ & & $89 \%$ & & $94 \%$ & & Enq. Prioritaire \\
\hline Secondary Access & Next secondary school within $30 \mathrm{~min}$ & $53 \%$ & & $46 \%$ & & $49 \%$ & & Enq. Prioritaire \\
\hline Healthcenter Access & Next health center within 30 min & $83 \%$ & & $77 \%$ & & $74 \%$ & & Enq. Prioritaire \\
\hline Market Access & Next market within $30 \mathrm{~min}$ & $95 \%$ & & $92 \%$ & & $90 \%$ & & Enq. Prioritaire \\
\hline Road & Access to road & & & $65 \%$ & & & & Enq. Communit. \\
\hline Freshwater & Access to fresh water point & & & $95 \%$ & & & & Enq. Communit. \\
\hline Market & Access to market & & & $55 \%$ & & & & Enq. Communit. \\
\hline School & Access to school & & & $67 \%$ & & & & Enq. Communit. \\
\hline Formation & Access to formation center & & & $6 \%$ & & & & Enq. Communit. \\
\hline Hospital & Access to hospital & & & $33 \%$ & & & & Enq. Communit. \\
\hline Pharmacy & Access to pharmacy & & & $31 \%$ & & & & Enq. Communit. \\
\hline Malaria & Malaria most frequent disease & & & $72 \%$ & & & & Enq. Communit. \\
\hline \multicolumn{9}{|l|}{ Provincial Level } \\
\hline Rain Mean & Avg rainfall in region in $\mathrm{ml}$ & 82.67 & 17.87 & 70.88 & 17.65 & 82.65 & 24.12 & Direc. of Meteo. \\
\hline Rain Var & Variation of rainfall & 12623 & 4678 & 7712 & 3376 & 10233 & 3627 & Direc. of Meteo. \\
\hline Pop Density & Population density & 24.39 & 58.35 & 18.88 & 50.44 & 21.00 & 59.44 & Minis. of Infra. \\
\hline Landsize & Avg size of cultivated land per $\mathrm{HH}$ in ha & & & 4.03 & 1.68 & 5.41 & 2.08 & Enq. Agricole \\
\hline Fertilizer & Use of fertilizer & & & $33 \%$ & & $15 \%$ & & Enq. Agricole \\
\hline Modern equipment & Use of modern agricult. equipment & & & $70 \%$ & & $69 \%$ & & Enq. Agricole \\
\hline \multicolumn{9}{|l|}{ Regional Level } \\
\hline Tempmax & Avg max temperature & 34.46 & 0.76 & 35.21 & 0.99 & 35.76 & 1.02 & Direc. of Meteo. \\
\hline Tarred Size & Density of tarred roads $(\mathrm{km} / \mathrm{km} 2)$ & 0.01 & 0.01 & 0.01 & 0.01 & 0.01 & 0.01 & Minis. of Infra. \\
\hline
\end{tabular}

Source: Authors' estimations, data sources see this Table.

* ZD (Zone de Dénombrement) is the French term for a cluster in the survey; it refers to the community level exploited throughout our analysis

** Variables are based on a fractionalization index $\mathrm{h}, h=1-\sum_{1}^{n} s_{i}^{2}$, where $s_{i}$ refers to the population share of the $i$ th ethnic or religious group. 
Table 3: Models - 1994 - Fixed effects

\begin{tabular}{|c|c|c|c|c|c|c|c|}
\hline & M0 & M1 & & M2 & & M4 & \\
\hline \multicolumn{8}{|l|}{ Household level } \\
\hline HH Size & & $\begin{array}{l}-0.040 \\
(0.001)\end{array}$ & $* * *$ & $\begin{array}{l}-0.040 \\
(0.001)\end{array}$ & $* * *$ & $\begin{array}{c}-0.042 \\
(0.002)\end{array}$ & $* * *$ \\
\hline Child Adult & & $\begin{array}{l}-0.054 \\
(0.006)\end{array}$ & $* * *$ & $\begin{array}{l}-0.052 \\
(0.006)\end{array}$ & $* * *$ & $\begin{array}{c}-0.042 \\
(0.006)\end{array}$ & $* * *$ \\
\hline Youth Adult & & $\begin{array}{l}-0.060 \\
(0.006)\end{array}$ & $* * *$ & $\begin{array}{l}-0.055 \\
(0.006)\end{array}$ & $* * *$ & $\begin{array}{l}-0.238 \\
(0.016)\end{array}$ & $* * *$ \\
\hline Age & & $\begin{array}{l}-0.006 \\
(0.001)\end{array}$ & $* * *$ & $\begin{array}{l}-0.006 \\
(0.001)\end{array}$ & $* * *$ & $\begin{array}{l}-0.004 \\
(0.001)\end{array}$ & $* * *$ \\
\hline Literate Head & & $\begin{array}{c}0.038 \\
(0.008)\end{array}$ & $* * *$ & $\begin{array}{c}0.036 \\
(0.008)\end{array}$ & $* * *$ & $\begin{array}{c}0.259 \\
(0.026)\end{array}$ & $* * *$ \\
\hline Literate Adult & & $\begin{array}{c}0.440 \\
(0.019)\end{array}$ & $* * *$ & $\begin{array}{c}0.367 \\
(0.020)\end{array}$ & $* * *$ & $\begin{array}{c}0.338 \\
(0.024)\end{array}$ & $* * *$ \\
\hline Christian & & $\begin{array}{c}0.056 \\
(0.020) \\
\end{array}$ & $* * *$ & $\begin{array}{c}0.049 \\
(0.019) \\
\end{array}$ & $* *$ & $\begin{array}{c}0.018 \\
(0.018) \\
\end{array}$ & \\
\hline \multicolumn{8}{|l|}{ Community level } \\
\hline ZD Ethnicity & & & & $\begin{array}{c}0.383 \\
(0.059)\end{array}$ & $* * *$ & $\begin{array}{c}0.281 \\
(0.054)\end{array}$ & $* * *$ \\
\hline ZD Literate Adult & & & & $\begin{array}{c}0.525 \\
(0.071)\end{array}$ & $* * *$ & $\begin{array}{c}0.385 \\
(0.065)\end{array}$ & $* * *$ \\
\hline ZD Youth Adult & & & & $\begin{array}{l}-0.093 \\
(0.042)\end{array}$ & $* *$ & $\begin{array}{l}-0.030 \\
(0.037)\end{array}$ & \\
\hline Electricity & & & & $\begin{array}{c}0.143 \\
(0.041)\end{array}$ & $* * *$ & $\begin{array}{c}0.157 \\
(0.037)\end{array}$ & $* * *$ \\
\hline Urban & & & & $\begin{array}{c}0.145 \\
(0.047) \\
\end{array}$ & $* * *$ & $\begin{array}{c}0.130 \\
(0.042) \\
\end{array}$ & $* * *$ \\
\hline Constant & $\begin{array}{c}11.080 \\
(0.070) \\
\end{array}$ & $\begin{array}{r}11.590 \\
(0.069) \\
\end{array}$ & & $\begin{array}{r}11.350 \\
(0.055) \\
\end{array}$ & & $\begin{array}{r}11.330 \\
(0.053) \\
\end{array}$ & \\
\hline $\mathrm{AIC}^{\dagger}$ & 19423 & 17065 & & 16780 & & 16187 & \\
\hline LR test ${ }^{\dagger \dagger}$ & 0.000 & - & & - & & 0.000 & \\
\hline No. of households & 8595 & 8595 & & 8595 & & 8595 & \\
\hline
\end{tabular}

Source: Authors' estimations, data sources see Table 2. Standard errors in parentheses. Significance level: *** $1 \%, * * 5 \%, * 10 \%$.

$\dagger$ Akaike Information Criterion.

${ }^{\dagger \dagger}$ For M0 the Likelihood Ratio (LR) test refers to: $H_{0}$ : The three-level model (household, community, province) performs better than the four-level model. Other tests were performed, but are not reported here (see Section 4.1). For Model M4: $H_{0}$ : M2 performs better than M4. 
Table 4: Models - 1998 - Fixed effects

\begin{tabular}{|c|c|c|c|c|c|c|c|c|c|c|c|}
\hline & M0 & M1 & & M2 & & M3 & & $\overline{\mathrm{M} 4}$ & & $\overline{\mathrm{M}^{*}}$ & \\
\hline \multicolumn{12}{|l|}{ Household level } \\
\hline HH Size & & $\begin{array}{l}-0.040 \\
(0.002)\end{array}$ & $* * *$ & $\begin{array}{c}-0.038 \\
(0.002)\end{array}$ & $* * *$ & $\begin{array}{c}-0.039 \\
(0.002)\end{array}$ & $* * *$ & $\begin{array}{c}-0.044 \\
(0.002)\end{array}$ & $* * *$ & $\begin{array}{c}-0.038 \\
(0.002)\end{array}$ & $* * *$ \\
\hline Child Adult & & $\begin{array}{l}-0.234 \\
(0.016)\end{array}$ & $* * *$ & $\begin{array}{l}-0.229 \\
(0.016)\end{array}$ & $* * *$ & $\begin{array}{c}-0.230 \\
(0.016)\end{array}$ & $* * *$ & $\begin{array}{c}-0.238 \\
(0.018)\end{array}$ & $* * *$ & $\begin{array}{l}-0.175 \\
(0.017)\end{array}$ & $* * *$ \\
\hline Youth Adult & & $\begin{array}{l}-0.180 \\
(0.015)\end{array}$ & $* * *$ & $\begin{array}{l}-0.169 \\
(0.015)\end{array}$ & $* * *$ & $\begin{array}{c}-0.169 \\
(0.015)\end{array}$ & $* * *$ & $\begin{array}{c}-0.163 \\
(0.014)\end{array}$ & $* * *$ & $\begin{array}{c}-0.148 \\
(0.015)\end{array}$ & $* * *$ \\
\hline Elderly Adult & & $\begin{array}{c}0.084 \\
(0.028)\end{array}$ & $* * *$ & $\begin{array}{c}0.091 \\
(0.028)\end{array}$ & $* * *$ & $\begin{array}{c}0.090 \\
(0.028)\end{array}$ & $* * *$ & $\begin{array}{c}0.093 \\
(0.028)\end{array}$ & $* * *$ & $\begin{array}{c}0.113 \\
(0.028)\end{array}$ & $* * *$ \\
\hline Age & & $\begin{array}{l}-0.006 \\
(0.001)\end{array}$ & $* * *$ & $\begin{array}{l}-0.006 \\
(0.001)\end{array}$ & $* * *$ & $\begin{array}{c}-0.006 \\
(0.001)\end{array}$ & $* * *$ & $\begin{array}{c}-0.006 \\
(0.001)\end{array}$ & $* * *$ & $\begin{array}{l}-0.006 \\
(0.001)\end{array}$ & $* * *$ \\
\hline Literate Head & & $\begin{array}{c}0.328 \\
(0.025)\end{array}$ & $* * *$ & $\begin{array}{c}0.277 \\
(0.025)\end{array}$ & $* * *$ & $\begin{array}{c}0.278 \\
(0.025)\end{array}$ & $* * *$ & $\begin{array}{c}0.270 \\
(0.025)\end{array}$ & $* * *$ & $\begin{array}{c}0.241 \\
(0.029)\end{array}$ & $* * *$ \\
\hline Literate Adult & & $\begin{array}{c}0.270 \\
(0.025)\end{array}$ & $* * *$ & $\begin{array}{c}0.253 \\
(0.025)\end{array}$ & $* * *$ & $\begin{array}{c}0.252 \\
(0.025)\end{array}$ & $* * *$ & $\begin{array}{c}0.214 \\
(0.029)\end{array}$ & $* * *$ & $\begin{array}{c}0.153 \\
(0.035)\end{array}$ & $* * *$ \\
\hline Cotton & & $\begin{array}{c}0.055 \\
(0.030)\end{array}$ & $*$ & $\begin{array}{c}0.084 \\
(0.029)\end{array}$ & $* * *$ & $\begin{array}{c}0.102 \\
(0.029)\end{array}$ & $* * *$ & $\begin{array}{c}0.107 \\
(0.028)\end{array}$ & $* * *$ & $\begin{array}{c}0.098 \\
(0.027)\end{array}$ & $* * *$ \\
\hline Muslim & & $\begin{array}{c}0.040 \\
(0.018) \\
\end{array}$ & $* *$ & $\begin{array}{c}0.036 \\
(0.017) \\
\end{array}$ & $* *$ & $\begin{array}{c}0.036 \\
(0.017) \\
\end{array}$ & $* *$ & $\begin{array}{c}0.052 \\
(0.017) \\
\end{array}$ & $* * *$ & $\begin{array}{c}0.057 \\
(0.019) \\
\end{array}$ & $* * *$ \\
\hline \multicolumn{12}{|l|}{ Community level } \\
\hline ZD Ethnicity & & & & $\begin{array}{c}0.212 \\
(0.064)\end{array}$ & $* * *$ & $\begin{array}{c}0.199 \\
(0.065)\end{array}$ & $* * *$ & $\begin{array}{c}0.135 \\
(0.060)\end{array}$ & $* *$ & $\begin{array}{c}0.106 \\
(0.058)\end{array}$ & $*$ \\
\hline ZD Literate Head & & & & $\begin{array}{c}0.696 \\
(0.099)\end{array}$ & $* * *$ & $\begin{array}{c}0.702 \\
(0.100)\end{array}$ & $* * *$ & $\begin{array}{c}0.454 \\
(0.098)\end{array}$ & $* * *$ & $\begin{array}{c}0.302 \\
(0.105)\end{array}$ & $* * *$ \\
\hline Electricity & & & & $\begin{array}{c}0.184 \\
(0.048)\end{array}$ & $* * *$ & $\begin{array}{c}0.197 \\
(0.048)\end{array}$ & $* * *$ & $\begin{array}{c}0.162 \\
(0.046)\end{array}$ & $* * *$ & $\begin{array}{c}0.113 \\
(0.052)\end{array}$ & $* *$ \\
\hline Urban & & & & $\begin{array}{c}0.129 \\
(0.049)\end{array}$ & $* *$ & $\begin{array}{c}0.195 \\
(0.050)\end{array}$ & $* * *$ & $\begin{array}{c}0.213 \\
(0.046)\end{array}$ & $* * *$ & $\begin{array}{c}0.340 \\
(0.054)\end{array}$ & $* * *$ \\
\hline Healthcenter Access & & & & 0.054 & $*$ & 0.060 & $*$ & 0.051 & $*$ & 0.023 & \\
\hline
\end{tabular}




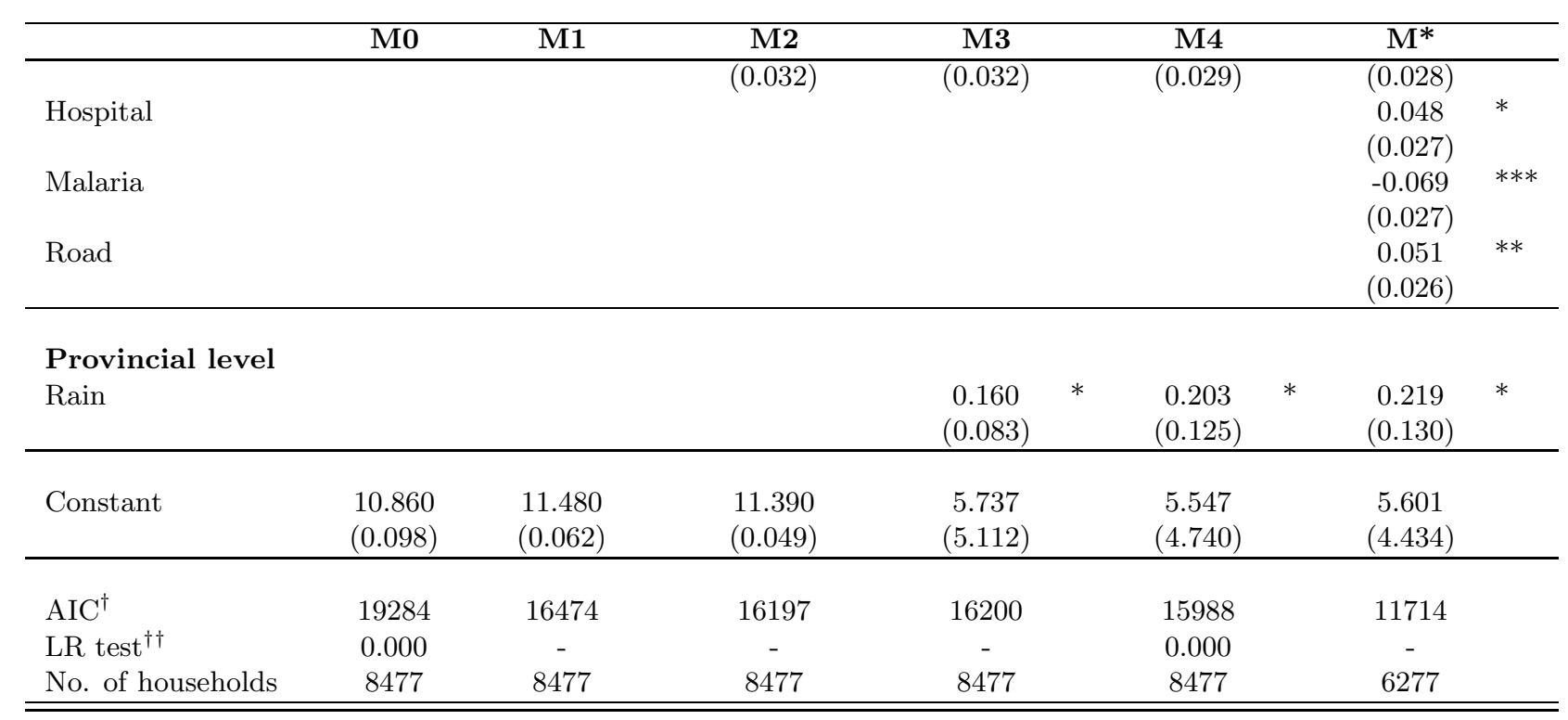

Source: Authors' estimations, data sources see Table 2. Standard errors in parentheses.

Significance level: $* * * 1 \%, * * 5 \%, * 10 \%$.

$\dagger$ Akaike Information Criterion.

${ }^{\dagger \dagger}$ For M0 the Likelihood Ratio (LR) test refers to: $H_{0}$ : The three-level model (household, community, province) performs better than the four-level model. Other tests were performed, but are not reported here (see Section 4.1). For Model M4: $H_{0}$ : M3 performs better than M4. 
Table 5: Models - 2003 - Fixed effects

\begin{tabular}{|c|c|c|c|c|c|c|c|}
\hline & M0 & M1 & & M2 & & M4 & \\
\hline \multicolumn{8}{|l|}{ Household level } \\
\hline HH Size & & $\begin{array}{c}-0.054 \\
(0.002)\end{array}$ & $* * *$ & $\begin{array}{c}-0.054 \\
(0.002)\end{array}$ & $* * *$ & $\begin{array}{l}-0.060 \\
(0.003)\end{array}$ & $* * *$ \\
\hline Child Adult & & $\begin{array}{c}-0.227 \\
(0.016)\end{array}$ & $* * *$ & $\begin{array}{c}-0.219 \\
(0.016)\end{array}$ & $* * *$ & $\begin{array}{l}-0.206 \\
(0.016)\end{array}$ & $* * *$ \\
\hline Youth Adult & & $\begin{array}{l}-0.190 \\
(0.015)\end{array}$ & $* * *$ & $\begin{array}{l}-0.178 \\
(0.015)\end{array}$ & $* * *$ & $\begin{array}{l}-0.183 \\
(0.015)\end{array}$ & $* * *$ \\
\hline Age & & $\begin{array}{c}-0.004 \\
(0.001)\end{array}$ & $* * *$ & $\begin{array}{c}-0.004 \\
(0.001)\end{array}$ & $* * *$ & $\begin{array}{c}-0.004 \\
(0.001)\end{array}$ & $* * *$ \\
\hline Sex & & $\begin{array}{l}-0.060 \\
(0.027)\end{array}$ & $* *$ & $\begin{array}{c}-0.064 \\
(0.027)\end{array}$ & $* *$ & $\begin{array}{l}-0.074 \\
(0.026)\end{array}$ & $* * *$ \\
\hline Literate Head & & $\begin{array}{c}0.272 \\
(0.024)\end{array}$ & $* * *$ & $\begin{array}{c}0.232 \\
(0.025)\end{array}$ & $* * *$ & $\begin{array}{c}0.252 \\
(0.025)\end{array}$ & $* * *$ \\
\hline Literate Adult & & $\begin{array}{c}0.268 \\
(0.023)\end{array}$ & $* * *$ & $\begin{array}{c}0.254 \\
(0.024)\end{array}$ & $* * *$ & $\begin{array}{c}0.212 \\
(0.028)\end{array}$ & $* * *$ \\
\hline Cotton & & $\begin{array}{c}0.079 \\
(0.028)\end{array}$ & $* * *$ & $\begin{array}{c}0.117 \\
(0.028)\end{array}$ & $* * *$ & $\begin{array}{c}0.105 \\
(0.028)\end{array}$ & $* * *$ \\
\hline Livestock & & $\begin{array}{c}0.034 \\
(0.020) \\
\end{array}$ & $*$ & $\begin{array}{c}0.083 \\
(0.020) \\
\end{array}$ & $* * *$ & $\begin{array}{c}0.096 \\
(0.020)\end{array}$ & $* * *$ \\
\hline \multicolumn{8}{|l|}{ Community level } \\
\hline ZD Livestock & & & & $\begin{array}{l}-0.362 \\
(0.094)\end{array}$ & $* * *$ & $\begin{array}{l}-0.369 \\
(0.090)\end{array}$ & $* * *$ \\
\hline ZD Literate Adult & & & & $\begin{array}{l}-0.240 \\
(0.128)\end{array}$ & $*$ & $\begin{array}{l}-0.291 \\
(0.124)\end{array}$ & $* *$ \\
\hline ZD Literate Head & & & & $\begin{array}{c}0.821 \\
(0.146)\end{array}$ & $* * *$ & $\begin{array}{c}0.706 \\
(0.144)\end{array}$ & $* * *$ \\
\hline Electricity & & & & $\begin{array}{c}0.142 \\
(0.048)\end{array}$ & $* * *$ & $\begin{array}{c}0.147 \\
(0.046)\end{array}$ & $* * *$ \\
\hline Market Access & & & & $\begin{array}{c}0.088 \\
(0.045) \\
\end{array}$ & $* *$ & $\begin{array}{c}0.075 \\
(0.042) \\
\end{array}$ & $*$ \\
\hline Constant & $\begin{array}{c}11.150 \\
0.095 \\
\end{array}$ & $\begin{array}{r}11.780 \\
(0.073) \\
\end{array}$ & & $\begin{array}{r}12.080 \\
(0.114) \\
\end{array}$ & & $\begin{array}{r}11.870 \\
(0.111) \\
\end{array}$ & \\
\hline $\mathrm{AIC}^{\dagger}$ & 19143 & 16305 & & 16135 & & 15982 & \\
\hline LR test ${ }^{\dagger \dagger}$ & 0.000 & - & & - & & 0.000 & \\
\hline No. of households & 8488 & 8488 & & 8488 & & 8488 & \\
\hline
\end{tabular}

Source: Authors' estimations, data sources see Table 2. Standard errors in parentheses. Significance level: *** $1 \%, * * 5 \%, * 10 \%$.

$\dagger$ Akaike Information Criterion.

${ }^{\dagger \dagger}$ For M0 the Likelihood Ratio (LR) test refers to: $H_{0}$ : The three-level model (household, community, province) performs better than the four-level model. Other tests were performed, but are not reported here (see Section 4.1). For Model M4: $H_{0}$ : M2 performs better than M4. 
Table 6: Models - 1994 - Random effects

\begin{tabular}{|c|c|c|c|c|c|c|c|c|}
\hline & \multicolumn{2}{|c|}{ M0 } & \multicolumn{2}{|c|}{ M1 } & \multicolumn{2}{|c|}{ M2 } & \multicolumn{2}{|c|}{ M4 } \\
\hline & Est. & Std.Err. & Est. & Std.Err. & Est. & Std.Err. & Est. & Std.Err. \\
\hline \multicolumn{9}{|l|}{ Variances } \\
\hline$\sigma_{w}^{2}$ & 0.075 & 0.047 & 0.043 & 0.023 & 0.016 & 0.008 & 0.015 & 0.008 \\
\hline$\sigma_{v}^{2}$ & 0.032 & 0.018 & 0.012 & 0.007 & 0.005 & 0.003 & 0.006 & 0.003 \\
\hline$\sigma_{u}^{2}$ & 0.171 & 0.014 & 0.087 & 0.008 & 0.034 & 0.004 & 0.091 & 0.012 \\
\hline$\sigma_{\epsilon}^{2}$ & 0.502 & 0.008 & 0.406 & 0.006 & 0.406 & 0.006 & 0.360 & 0.006 \\
\hline $\operatorname{var}($ hhsize $)$ & & & & & & & 0.000 & 0.000 \\
\hline $\operatorname{var}($ youth adult) & & & & & & & 0.018 & 0.006 \\
\hline var(literate head) & & & & & & & 0.055 & 0.013 \\
\hline \multicolumn{9}{|l|}{ Covariances } \\
\hline $\operatorname{cov}($ hhsize, youth adult) & & & & & & & 0.000 & 0.001 \\
\hline cov(hhsize, lit. head) & & & & & & & -0.002 & 0.001 \\
\hline $\operatorname{cov}($ youth ad, lit. head $)$ & & & & & & & -0.007 & 0.007 \\
\hline $\operatorname{cov}\left(\right.$ hhsize, $\left.U_{j k l}\right)$ & & & & & & & -0.005 & 0.001 \\
\hline $\operatorname{cov}\left(\right.$ youth ad, $\left.U_{j k l}\right)$ & & & & & & & -0.018 & 0.007 \\
\hline $\operatorname{cov}\left(\right.$ literate head, $\left.U_{j k l}\right)$ & & & & & & & 0.009 & 0.009 \\
\hline
\end{tabular}

Source: Authors' estimations, data sources see Table 2.

Table 7: Models - 1998 - Random effects

\begin{tabular}{|c|c|c|c|c|c|c|c|c|c|c|}
\hline & \multicolumn{2}{|c|}{ M0 } & \multicolumn{2}{|c|}{ M1 } & \multicolumn{2}{|c|}{ M2 } & \multicolumn{2}{|c|}{ M3 } & \multicolumn{2}{|c|}{ M4 } \\
\hline & Est. & Std.Err. & Est. & Std.Err. & Est. & Std.Err. & Est. & Std.Err. & Est. & Std.Err. \\
\hline \multicolumn{11}{|l|}{ Variances } \\
\hline$\sigma_{w}^{2}$ & 0.078 & 0.048 & 0.027 & 0.020 & 0.005 & 0.004 & 0.006 & 0.005 & 0.005 & 0.004 \\
\hline$\sigma_{v}^{2}$ & 0.025 & 0.016 & 0.017 & 0.010 & 0.009 & 0.005 & 0.009 & 0.005 & 0.009 & 0.009 \\
\hline$\sigma_{u}^{2}$ & 0.221 & 0.018 & 0.100 & 0.009 & 0.040 & 0.004 & 0.041 & 0.004 & 0.104 & 0.104 \\
\hline$\sigma_{\epsilon}^{2}$ & 0.510 & 0.008 & 0.388 & 0.006 & 0.387 & 0.006 & 0.387 & 0.006 & 0.357 & 0.357 \\
\hline $\operatorname{var}($ hhsize $)$ & & & & & & & & & 0.001 & 0.000 \\
\hline $\operatorname{var}$ (Children adult) & & & & & & & & & 0.027 & 0.008 \\
\hline $\operatorname{var}($ literate head $)$ & & & & & & & & & 0.085 & 0.016 \\
\hline \multicolumn{11}{|l|}{ Covariances } \\
\hline cov(hhsize,Child adult) & & & & & & & & & 0.002 & 0.001 \\
\hline $\operatorname{cov}($ hhsize, lit. head) & & & & & & & & & -0.003 & 0.001 \\
\hline cov(Child ad, lit. head) & & & & & & & & & -0.026 & 0.008 \\
\hline $\operatorname{cov}\left(\right.$ hhsize,$\left.U_{j k l}\right)$ & & & & & & & & & -0.006 & 0.001 \\
\hline $\operatorname{cov}\left(\right.$ Children ad, $\left.U_{j k l}\right)$ & & & & & & & & & -0.031 & 0.009 \\
\hline $\operatorname{cov}\left(\right.$ lit. head, $\left.U_{j k l}\right)$ & & & & & & & & & 0.038 & 0.011 \\
\hline
\end{tabular}

Source: Authors' estimations, data sources see Table 2. 
Table 8: Models - 2003 - Random effects

\begin{tabular}{|c|c|c|c|c|c|c|c|c|}
\hline & \multicolumn{2}{|c|}{$\overline{\text { M0 }}$} & \multicolumn{2}{|c|}{$\overline{\text { M1 }}$} & \multicolumn{2}{|c|}{ M2 } & \multicolumn{2}{|c|}{$\overline{\mathrm{M} 4}$} \\
\hline & Est. & Std.Err. & Est. & Std.Err. & Est. & Std.Err. & Est. & Std.Err. \\
\hline \multicolumn{9}{|l|}{ Variances } \\
\hline$\sigma_{w}^{2}$ & 0.085 & 0.045 & 0.032 & 0.021 & 0.019 & 0.013 & 0.019 & 0.0137 \\
\hline$\sigma_{v}^{2}$ & 0.025 & 0.013 & 0.032 & 0.012 & 0.037 & 0.011 & 0.041 & 0.0122 \\
\hline$\sigma_{u}^{2}$ & 0.157 & 0.013 & 0.078 & 0.007 & 0.042 & 0.005 & 0.066 & 0.0114 \\
\hline$\sigma_{\epsilon}^{2}$ & 0.502 & 0.008 & 0.376 & 0.006 & 0.375 & 0.006 & 0.350 & 0.0059 \\
\hline $\operatorname{var}($ hhsize $)$ & & & & & & & 0.001 & 0.000 \\
\hline $\operatorname{var}($ youth adult $)$ & & & & & & & 0.005 & 0.004 \\
\hline $\operatorname{var(literate~head)}$ & & & & & & & 0.074 & 0.014 \\
\hline \multicolumn{9}{|l|}{ Covariances } \\
\hline $\operatorname{cov}($ hhsize, youth adult) & & & & & & & 0.002 & 0.0007 \\
\hline $\operatorname{cov}($ hhsize, lit. head $)$ & & & & & & & -0.003 & 0.0011 \\
\hline $\operatorname{cov}($ youth ad, lit. head $)$ & & & & & & & -0.012 & 0.0069 \\
\hline $\operatorname{cov}\left(\right.$ hhsize, $\left.U_{j k l}\right)$ & & & & & & & -0.004 & 0.0011 \\
\hline $\operatorname{cov}\left(\right.$ youth ad, $\left.U_{j k l}\right)$ & & & & & & & -0.013 & 0.0061 \\
\hline $\operatorname{cov}\left(\right.$ literate head, $\left.U_{j k l}\right)$ & & & & & & & 0.016 & 0.0094 \\
\hline
\end{tabular}

Source: Authors' estimations, data sources see Table 2.

Table 9: Contribution of observed and unobserved characteristics on the variation at each level

\begin{tabular}{|c|c|c|c|c|}
\hline & & 1994 & 1998 & 2003 \\
\hline$\rho_{H H}$ & Household level & $64.4 \%$ & $61.2 \%$ & $65.2 \%$ \\
\hline$\Delta \sigma_{\epsilon_{H H}}^{2}$ & Household variables & $19.1 \%$ & $23.9 \%$ & $25.1 \%$ \\
\hline $1-\Delta \sigma_{\epsilon_{H H}}^{2}$ & Unobserved & $80.9 \%$ & $76.1 \%$ & $74.9 \%$ \\
\hline$\rho_{C}$ & Community level & $21.9 \%$ & $26.5 \%$ & $20.5 \%$ \\
\hline$\Delta \sigma_{u_{C}}^{2}$ & Community variables & $31.1 \%$ & $27.5 \%$ & $22.7 \%$ \\
\hline$\Delta \sigma_{u_{H H}}^{u_{C}}$ & Household variables & $49.1 \%$ & $54.6 \%$ & $50.3 \%$ \\
\hline $1-\Delta \sigma_{u_{H} H}^{2}-\Delta \sigma_{u_{C}}^{2}$ & Unobserved & $19.8 \%$ & $17.9 \%$ & $27.0 \%$ \\
\hline$\rho_{P}$ & Provincial level & $4.1 \%$ & $3.0 \%$ & $3.3 \%$ \\
\hline$\Delta \sigma_{v_{P / R}}^{2}$ & Provincial/Regional variables & $0 \%$ & $1.2 \%$ & $0 \%$ \\
\hline$\Delta \sigma_{v_{C}}^{2}$ & Community variables & $21.7 \%$ & $29.8 \%$ & $0 \%$ \\
\hline$\Delta \sigma_{v_{H H}}^{2}$ & Household variables & $64.0 \%$ & $33.7 \%$ & $20.5 \%$ \\
\hline $1-\Delta \sigma_{v_{H H}}^{2}-\Delta \sigma_{v_{C}}^{2}-\Delta \sigma_{v_{P / R}}^{2}$ & Unobserved & $14.3 \%$ & $35.3 \%$ & $79.5 \%$ \\
\hline$\rho_{R}$ & Regional level & $9.6 \%$ & $9.3 \%$ & $11.1 \%$ \\
\hline$\Delta \sigma_{w_{P / R}}^{2}$ & Provincial/Regional variables & $0 \%$ & $0 \%$ & $0 \%$ \\
\hline$\Delta \sigma_{w_{C}}^{2}$ & Community variables & $35.7 \%$ & $27.5 \%$ & $15.9 \%$ \\
\hline$\Delta \sigma_{w_{H H}}^{\omega_{C}}$ & Household variables & $42.5 \%$ & $65.4 \%$ & $62.4 \%$ \\
\hline $1-\Delta \sigma_{w_{H} H}^{2}-\Delta \sigma_{w_{C}}^{2}-\Delta \sigma_{w_{P} R}^{2}$ & Unobserved & $21.8 \%$ & $7.1 \%$ & $21.7 \%$ \\
\hline
\end{tabular}

Source: Authors' estimations, data sources see Table 2. 